\title{
The Analysis and Research of Multi-Sport Cooperative Learning based on Association Rule Mining and Mathematical Statistics Analysis
}

\author{
Ping $\mathrm{Li}^{*}$ and Linting $\mathrm{Ma}$ \\ Department of Physical Education, Inner Mongolia University of \\ Science\&Technology, Baotou, Inner Mongolia, China, 014010 \\ 1274834790@qq.com,50316211@qq.com
}

\begin{abstract}
Based on education, cognitive psychology and constructivism learning theory, this paper put forward multiple cooperative motion recognition strategy, and established the multi-sport cooperative learning model, namely, the cooperation from teachers to group experts, and then to multimedia, finally to learners. In order to verify the validity, we designed and implemented the questionnaire and teaching experiment, taking students from Inner Mongolia University of Science and Technology as the research object, and analyzed the experimental data by means of association rule mining technique and mathematical statistical analysis. Analysis results show that multiple collaborative learning methods can effectively enhance students learning interests of physical study and improve their physical skills, helping to cultivate the ability of cooperative learning among students. The association rules mining results show that teaching strategy has a very high correlation with the method, and using group cooperation synchronization classroom teaching can achieve the best teaching effect.
\end{abstract}

Keywords: physical cooperative learning; multi model; mathematical statistics analysis; association rule mining

\section{Introduction}

Collaborative learning is based on constructivism learning theory and humanism learning theory [1]. Constructivism holds that the knowledge gained is not just the result of teaching, but also obtained by learners that in certain contexts, namely, the social and cultural background, with the help of others (including teachers and collaboration partners), use the necessary learning materials to achieve it through the meaning construction method [2]. Constructivism learning theory believes that the "situation", "cooperation", "conversation" and "meaning construction" are the four main elements of learning environment [3]. Besides, another important theoretical basis of collaborative learning is Rogers learning theory [4], which emphasizes the dedication of study and free study, and learners themselves have learning ability that only when the learning conforms to their purpose own, will it be meaningful. This theory also claims that when learners take part in the learning process seriously, then their study will be promoted, and spontaneous learning involving individual learners (including mental and emotional) is most lasting and profound. Companion teaching and group learning can both promote study. Thus, both constructivism and humanism learning theory emphasize the role of oneself and environment in learning. Learning is the process of acquiring knowledge, but knowledge is merely not taught by teachers, but also obtained by learners that in certain contexts, namely, the social and cultural background, with the help of others (including teachers and collaboration partners), use the necessary learning materials to achieve it through the meaning construction method [2]. Constructivism learning theory believes 
that the "situation", "cooperation", "conversation" and "meaning construction" are the four main elements of learning environment.

Multi sports cooperative learning refers to all relative learning behaviors that learners in the form of individuals or groups [5], under common physical education learning goals and certain incentive mechanism, master the skills, tactics and related knowledge of physical training through the mutual collaboration between teachers and students, between students, between teachers and students and the computer and network.

Based on this, the author design the experiment according to multi sports collaborative learning theory, setting the experimental group and the control group to compare the experimental process. The experimental contents are the badminton cooperative learning situation of students from 2012 to 2015 grades in Inner Mongolia University of Science and Technology. The experimental results are analyzed comprehensively by association rule mining and mathematical statistics analysis method, which helps to make summaries and recommendations.

\section{Experimental objects and processes}

\subsection{Experimental objects}

We extract 300 people (140 as the experimental group, the control group of 160 people) from the badminton class of 2012 to 2015 grades of the Department of Physical Education in Inner Mongolia University of Science and Technology as the research objects, using random sampling method. There into, the experimental group has 108 boys and 32 girls, while the control group includes 128 boys and 32 girls.

\subsection{Experimental hypotheses}

In order to study the effect of multiple cooperation learning system on PE learning, the main assumption of this paper is that the corresponding relation between three indexes, namely students' learning interest, learning attitude and learning achievement, and systematic strategies of multiple collaborative learning. In the experiment, the three hypothetical indexes showed the tendency that the experimental group has done a better job than the control group.

\subsection{Experimental pretreatment}

By making experimental invitation to call the appropriate subjects to take part in the experiment, the experiment was divided into experimental group and control group. Before the experiment, we carried out physical fitness test and badminton technology assessment on samples, including height, weight, vital capacity, standing long jump, grip strength, step test, badminton serve and backcourt clean catching. The following Table 1-3 shows the basic physical fitness and badminton technical evaluation of the experimental group and the control group before the experiment.

Table 1. Physical Quality Measurement of Boys in the Experimental Group and the Control Group

\begin{tabular}{|l|l|l|l|l|l|l|l|}
\hline Groups & Height/cm & $\begin{array}{l}\text { Weight } \\
/ \mathrm{kg}\end{array}$ & $\begin{array}{l}\text { Vital } \\
\text { Capacity }\end{array}$ & $\begin{array}{l}\text { Long } \\
\text { Jump/cm }\end{array}$ & $\begin{array}{l}\text { High } \\
\text { Jump/cm }\end{array}$ & Grip/kg & $\begin{array}{l}\text { Step } \\
\text { exam/index }\end{array}$ \\
\hline Experimental & $174.5 \pm 4.8$ & $60.3 \pm 6.2$ & $3847 \pm 639$ & $54.7 \pm 12.4$ & $39 \pm 5.7$ & $53.4 \pm 5.8$ & $83.4 \pm 5.2$ \\
\hline Control & $173.9 \pm 4.3$ & $60.1 \pm 6.1$ & $3748 \pm 701$ & $52.4 \pm 11.9$ & $38 \pm 4.8$ & $54.1 \pm 5.2$ & $85.7 \pm 7.1$ \\
\hline $\mathrm{t}$ & 0.9348 & 0.1736 & 1.4873 & 2.1837 & 0.5837 & 0.5293 & 0.2982 \\
\hline $\mathrm{P}$ & 0.1817 & 0.4837 & 0.0729 & 0.0293 & -0.0837 & 0.2974 & 0.4823 \\
\hline
\end{tabular}


Table 2. Physical Quality Measurements of Girls in the Experimental Group and the Control Group

\begin{tabular}{|l|l|l|l|l|l|l|l|}
\hline Groups & Height/cm & $\begin{array}{l}\text { Weight } \\
/ \mathrm{kg}\end{array}$ & $\begin{array}{l}\text { Vital } \\
\text { Capacity }\end{array}$ & $\begin{array}{l}\text { Long } \\
\text { Jump/cm }\end{array}$ & $\begin{array}{l}\text { High } \\
\text { Jump/cm }\end{array}$ & Grip/kg & $\begin{array}{l}\text { Step } \\
\text { exam/index }\end{array}$ \\
\hline Experimental & $1.57 \pm 4.6$ & $49.4 \pm 3.2$ & $2549 \pm 453$ & $175 \pm 14$ & $19 \pm 4.2$ & $34.6 \pm 2.7$ & $45.9 \pm 3.2$ \\
\hline Control & $1.60 \pm 3.9$ & $48.9 \pm 5.7$ & $2673 \pm 458$ & $183 \pm 18$ & $18 \pm 3.7$ & $33.8 \pm 3.8$ & $47.8 \pm 4.8$ \\
\hline $\mathrm{t}$ & -1.0394 & -0.3847 & 1.9038 & 0.4823 & -0.0583 & 0.3948 & 0.2934 \\
\hline $\mathrm{P}$ & 0.1498 & 0.2394 & 0.1493 & 0.3482 & 0.4539 & 0.3847 & 0.3480 \\
\hline
\end{tabular}

Table 3. Statistics of the Technical Situation of the Experimental Group and Control Group

\begin{tabular}{|l|l|l|}
\hline Groups & Service balls & Catch high balls \\
& $\bar{X} \pm S$ & $\bar{X} \pm S$ \\
\hline Experimental(n=128) & $53.58 \pm 8.85$ & $46.38 \pm 12.49$ \\
\hline Control(n=145) & $58.48 \pm 11.89$ & $46.47 \pm 14.73$ \\
\hline $\mathrm{t}$ & -1.4593 & 0.1738 \\
\hline $\mathrm{P}$ & 0.0948 & 0.4983 \\
\hline
\end{tabular}

Here, $\mathrm{t}, \mathrm{p}$ represent the control parameters for the sampling error (assuming $\mathrm{t}$ test and the confidence parameter $\mathrm{P}$, the calculation method will be given in the later passage). After the test and analysis of the whole class, the confidence of $95 \%$ is determined, so as to determine the confidence interval. Make statistics after excluding the objectives which are not in the confidence interval of both groups, ensuring the homogeneity of research objects. Eventually 128 were selected as the objects of experimental group, 145 for the control group. Through $\mathrm{t}$ test, there showed no significant difference between them $(P>0.05)$. The results are shown in Figure 1-3.

\subsection{Experimental process}

The experimental group: apply factors on the synchronous collaborative learning of multimedia aided classroom teaching. According to the needs of teaching and site, students are divided into several cooperative learning groups, usually 3-5 groups, each with a group leader and group experts to carry out the division of labor. In the learning process, each group according to the plan to conduct multimedia teaching and cooperative learning, as well as teacher-student interaction; group beginners mainly to set up the correct action concept; group experts cooperate with each other, mainly to fully master the technical movements and correct wrong actions, and part of experts master learning and practicing methods to carry out cooperative learning with the group beginners, so as to make sure that every group member has mastered this movement and knowledge of this technique [6-7]. The experiment group uses the teaching method of multi PE cooperative learning. The teaching and learning strategies of this method are shown in Figure 1.

The control group: use the traditional approaches of teachers' oral explanation, action modeling, students' practice, and teachers' guidance. In addition to the different factors imposed on teaching method, other conditions of the experimental group and the control group are almost the same as both are taught by the same teacher, with the same teaching content, testing content and method of the same. The experiment time was from July to December in 2015, a total of 20 weeks, 2 periods a week. 


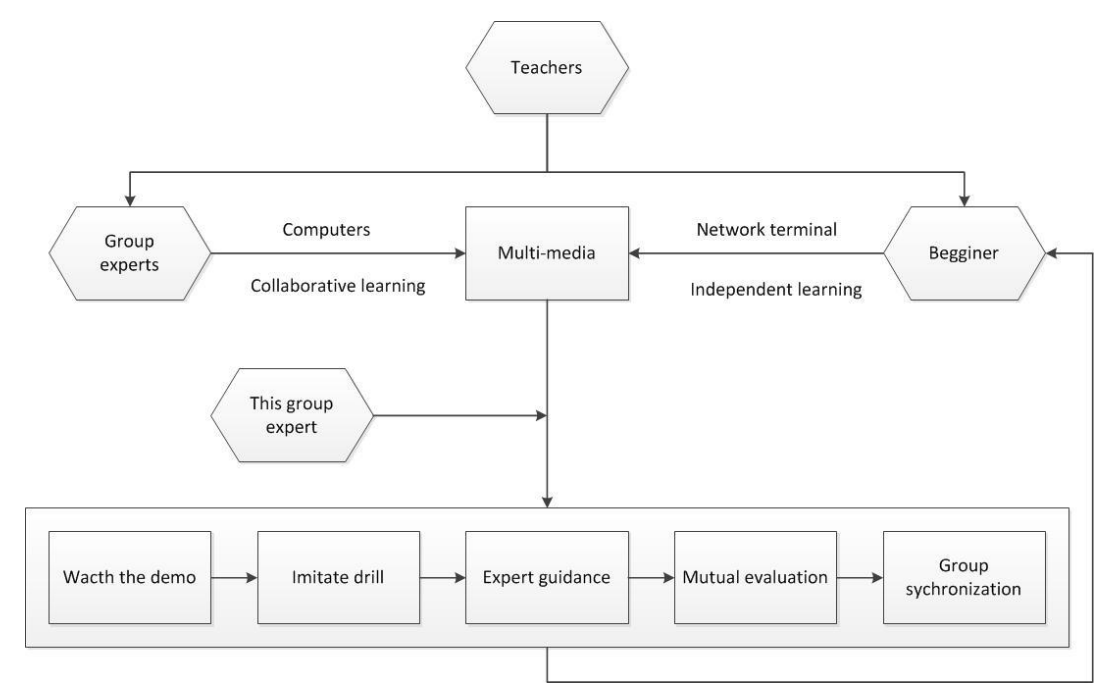

Figure 1. Multi PE Collaboration Teaching and Learning Strategy Model

\subsection{Experimental Content and Evaluation Index}

Between the experimental group and the control group, we conducted the following several teaching contents related to the basic action, strengthened action and sports completion of badminton.

(1) Learn forehand lofty ball;

(2) Learn the forehand lob, drop shot, toe lift;

(3) Learn forehand and backhand chopping, pushball, smash;

(4) Learn basic steps;

(5) Understand the basic tactics of single doubles;

(6) Understand single, doubles competition method, competition rules and the referee method;

Besides the above 6 basic and enhanced actions and related sports teaching contents, we also need to test and evaluate the performance of the experimental group and the control group completed by adopting double blind method to carry out skill evaluation and standard test on students' badminton learning situation after the end of the experiment.

Skill assessment means that teachers make qualitative evaluation on the correctness, standardization and rationality of students' movement, which is divided into five levels: upper, middle upper, middle, middle lower and lower. The levels were then converted into the standard percentage through grade standard $\mathrm{Z}$ calculation to do statistical analysis and association rules mining. The standard test conducts test and evaluation based on the stability of technology.

\subsection{Experimental analysis method}

$\mathbf{t}$ test and confidence interval P:The significant test is a statistical analysis technique that uses the sample information, according to a certain probability level, to infer the index and the overall index, and also to check whether the difference different samples have any significance [8]. With this method, we can determine whether statistics are reliable, and the possibility of reliable data. In the contrast experiment of this paper, since the acquisition and analysis process of the data are under no confidence condition, so the significant test can be used to complete the test. $t$ test is a significant test used commonly in hypothesis testing of the data of one or two samples' numerical variables, with $t$ 
distribution as its theoretical basis [9]. It belongs to the parameter detection method. In the contrast experiment, there are two groups of contrast samples, so the use of double overall $\mathrm{t}$ test can complete the significant test of the sample.

The double overall $t$ test is used to examine whether the difference between the average value of the two kinds of samples and their respective total is significant. In this paper, we adopt the independent sample $t$ test, and the test method is as follows:

Firstly, the mean and variance of the two kinds of samples are calculated respectively, and the calculation method of mean and variance is given by the following formula (1-2).

$$
\begin{gathered}
\bar{X}=\frac{1}{N} \sum_{i=1}^{N} X_{i} \\
S^{2}=\frac{1}{N-1} \sum_{i=1}^{N}\left(X_{i}-\bar{X}\right)^{2}
\end{gathered}
$$

Here, $\mathrm{N}$ represents the amount of corresponding category sample. As for the two kinds of samples, based on formula (1-2), we can figure out the corresponding mean and variance, $\bar{X}_{1}, \bar{X}_{2}, S_{1}^{2}, S_{2}^{2}$ and then according to formula (3) and the statistical date to calculate $t$ test value.

$$
t=\frac{\bar{X}_{1}-\bar{X}_{2}}{\sqrt{\frac{\left(N_{1}-1\right) S_{1}^{2}+\left(N_{2}-1\right) S_{2}^{2}}{N_{1}+N_{2}-2}\left(\frac{1}{N_{1}}+\frac{1}{N_{2}}\right)}}
$$

According to the above calculation way, we can figure out the $t$ value of every sample, and make a table of $t$ value. In the significance test, the population distribution of the hypothesis sample of t test $H_{0}$ is normal distribution. P refers to the possibility of being equal to or greater than (equal to or lower than) the available statistics magnitude when the totality make random sampling required by null hypothesis. Comparing the $\mathrm{t}$ value obtained with the $\mathrm{t}$ value in table, if $t^{\prime}<t$, then $P>\alpha$, which means it does not refuse sample $H_{0}$, indicating that there is no significant difference between the two samples; otherwise, if $P>\alpha$, then this means that it refuses sample $H_{0}$, indicating that there is significant difference between the two samples; The threshold value of this experiment is $\alpha=0.05$. According to $\mathrm{T}$ test and the calculation results of $\mathrm{P}$ value, we can analyze whether the corresponding data have any practical meaning. From Figure 1-3, it can be seen that the research objects of the two groups have no significant difference (the data in the figure show that $P>0.05$ )

Association Rule Mining Algorithm: Association rules refer to the rules generated from the reduction of a variety of complex and redundant attributes [10]. In multiple sports cooperation model, multiple attributes can affect the process of PE learning. through the method of mining association rules, we can analyze meaningful data from numerous data, and extract attributes which have an important factor on PE writing learning, and these attributes belong to the frequent set [11].

Suppose that set $\mathrm{I}$ means $\mathrm{m}$ criminal cases information without categories $I=\left\{i_{1}, i_{2}, \ldots, i_{m}\right\}$. Each type of case information is called project, and the set $\mathrm{I}$ is named item set. Set $\mathrm{D}$ represents transactional databases, while $D=\left\{T_{1}, T_{2}, \ldots, T_{m}\right\}$ means the data set of criminal behavior characteristics, and each kind of criminal behavior feature is named affair. Since each case has a variety of criminal behavior characteristics, so the collection $\mathrm{T}$ of each affair should be the subset of item set I, having a containing relation. In the process of identifying a transaction, we should determine a unique 
identifier $T I D$ for each transaction.

Suppose that $\mathrm{X}, \mathrm{Y}$ is two different subsets, and $X \subseteq T, Y \subseteq T ?, X \cap Y=\phi$, since in the inference of the association rules of criminal behavior, the association rules relation is usually exists in the form of $X \Rightarrow Y$. As for the association rules relation, generally, we can use the following confidence and support to measure the relationship of each association rule.

(1) Confidence: means that there are the percentages of both $X$ and $Y$ in the database D, through which the certainty between $\mathrm{X}$ and $\mathrm{Y}$ can be described, namely the confidence of the association rule.

(2) Support: refers to the percentage of the association relation part owned by $\mathrm{X}, \mathrm{Y}$ in the $\mathrm{D}$ transactional database, which is used to show the usable degree of association rule in data collection.

The indexes for judging the frequent item sets are minimum support $M_{s}$ and minimum confidence $M_{c}$. Obtain meaningful association rule through the calculation results of the following formula to compare the two thresholds.

$$
\begin{gathered}
M_{c}=\text { Confidence }(X \Rightarrow Y)=P(X \mid Y) \\
M_{s}=\operatorname{Support}(X \Rightarrow Y)=P(X \cup Y)
\end{gathered}
$$

If the support of sub item set $\mathrm{X}$ or $\mathrm{Y}$ is not lower than the minimum support threshold $M_{s}$, then $\mathrm{X}$ can be regarded as frequent item set. If both the supports of sub item set $\mathrm{X}$ and $\mathrm{Y}$ are not less than the corresponding minimum threshold, then it can be considered that the implicated association rule extracted $X \Rightarrow Y$ is strong rule, which has strong confidence, and has great meaning in operation. Therefore, we can use association rules mining algorithms to find out all of the strong rules from database D as the mining results.

\section{The Analysis and Conclusion of the Experiment Results}

\subsection{The Influence of the Cooperative Model on Learning Interest}

The survey results show that: the average score of learning interest of the experimental group is 47.38 , and that of the control group is 42.46 , indicating that the experimental group is better than the control group in this aspect. Conduct $t$ test on survey results of students' interest in learning, the experimental results of the two groups are shown in Figure 4. It indicates that there is a significant difference between the two groups ( $P=0.014<0.05)$. The effect of random error is eliminated, so the experimental factors are effective to improve the students' learning interest. Through reason analysis, it can be seen that the sports interest refers to the psychological tendency of student to strive for the positive understanding of sports activities and the priority of engaging e physical exercise, which is one of the basic power for students to participate in the sports activity [12].

In traditional teaching, teachers' demonstration takes up a lot of time, so students become passive recipients. In contrast, in multi sports collaborative teaching, teachers meet the needs of students to participate in learning and exercise, encouraging students to participate actively, attempt boldly, and the exchanges between teachers and students are increased, thus to produce interaction in emotion and thinking process to maximize the enthusiasm of students, making students become the subject of study. In addition, the vivid multimedia teaching resources also has a positive effect on students' interest. 
Table 4. The Contrast of Learning Interest in the Experimental Group and the Control Group

\begin{tabular}{|l|l|l|l|l|l|}
\hline Groups & Numbers & Average & $\begin{array}{l}\text { Standard } \\
\text { deviation }\end{array}$ & $\mathrm{t}$ & $\mathrm{P}$ \\
\hline Experimental & 128 & 47.38 & 6.9 & 2.2349 & 0.0149 \\
\hline Control & 145 & 42.46 & 7.0 & 1.4958 & 0.0458 \\
\hline
\end{tabular}

\subsection{The Influence of the Multi-Sport Collaboration Model on the Learning Attitude}

Figure 2 shows the results comparison between the experimental group and the control group, which show that the performance of the experimental group in 3 dimensions, namely, the target attitude, behavioral cognition and emotional experience before and after the test are all higher than the control group, indicating that the improvement range of exercise attitude in the experimental group is better than the control group, while in behavioral habit, the former is lower than the latter. From the $t$ test of research results, the attitude analysis results are displayed in Figure 5 and Figure 6. In the aspects of target attitude and emotional experience, there is significant difference in the students of the experimental group $(P<0.01)$, while the control group has significant difference in behavioral recognition $(P<0.05)$. It shows that the experimental group students perform better in exercise attitude than that of the control group students. It is the experiment that promotes students to perform good exercise attitude. But there is no significant difference in behavioral habits of both groups $(P>0.05)$, indicating that the experiment has no significant effect on the cultivation of students' lifelong physical exercise habit.

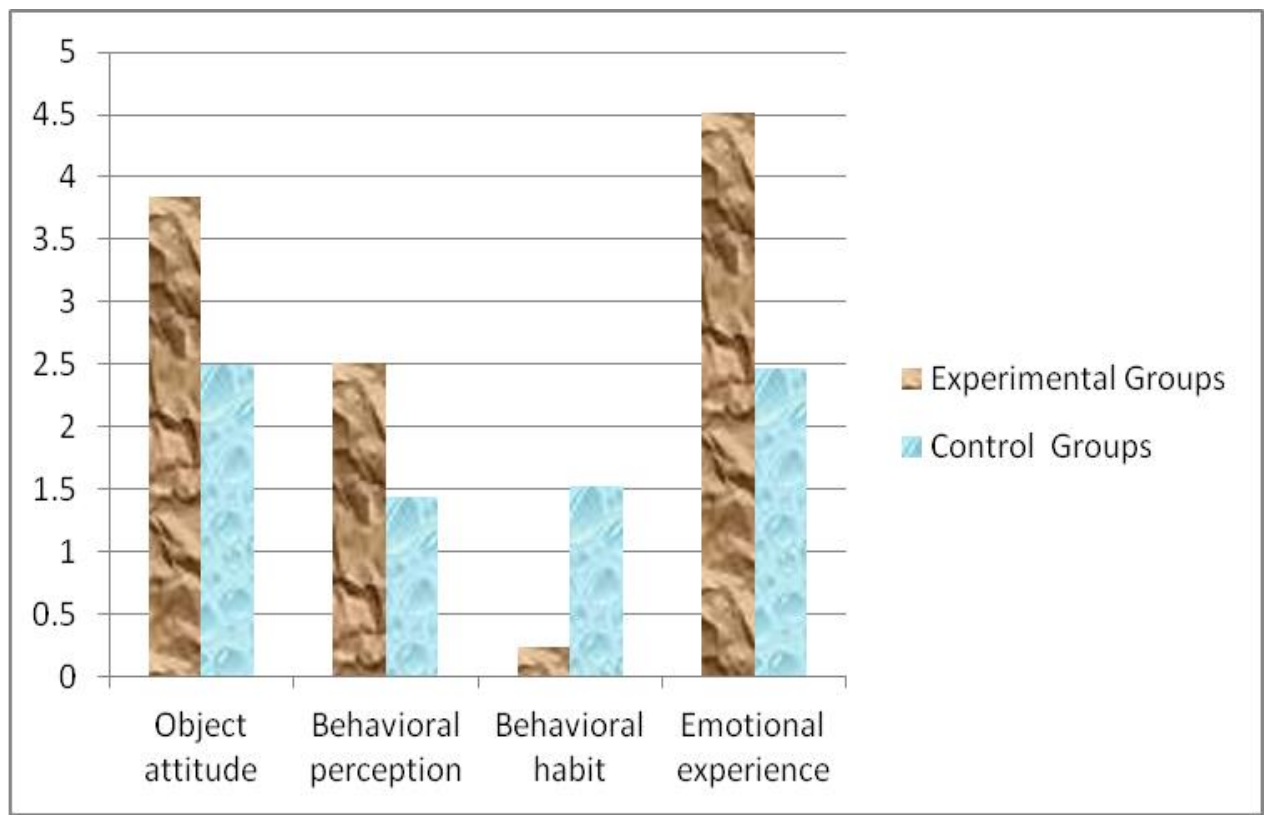

Figure 2. Comparison Results of Learning Attitude 
Table 5. $t$ test Results Analysis of Experimental Group Learning Attitude

\begin{tabular}{|c|c|c|c|c|c|c|c|c|}
\hline \multirow[t]{2}{*}{ Content } & \multicolumn{2}{|c|}{ Object attitude } & \multicolumn{2}{|c|}{$\begin{array}{l}\text { Behavioral } \\
\text { perception }\end{array}$} & \multicolumn{2}{|c|}{$\begin{array}{l}\text { Behavioral } \\
\text { habit }\end{array}$} & \multicolumn{2}{|c|}{$\begin{array}{l}\text { Emotional } \\
\text { experience }\end{array}$} \\
\hline & Before & After & Before & After & Before & After & Before & After \\
\hline Average & 38.49 & 43.48 & 22.39 & 25.69 & 12.39 & 12.27 & 20.48 & 24.03 \\
\hline Variance & 3.74 & 6.52 & 8.07 & 17.18 & 25.98 & 14.13 & 16.08 & 17.18 \\
\hline $\mathrm{t}$ & \multicolumn{2}{|l|}{1.7391} & \multicolumn{2}{|l|}{1.7839} & \multicolumn{2}{|l|}{1.7639} & \multicolumn{2}{|l|}{1.7947} \\
\hline $\mathrm{P}$ & \multicolumn{2}{|l|}{0.0048} & \multicolumn{2}{|l|}{0.4938} & \multicolumn{2}{|l|}{0.0948} & \multicolumn{2}{|l|}{0.0084} \\
\hline
\end{tabular}

Table 6. $t$ test Results Analysis of Control Group Learning Attitude

\begin{tabular}{|l|l|l|l|l|l|l|l|l|}
\hline \multirow{2}{*}{ Content } & \multicolumn{2}{l|}{ Object attitude } & \multicolumn{2}{l|}{$\begin{array}{l}\text { Behavioral } \\
\text { perception }\end{array}$} & \multicolumn{3}{l|}{$\begin{array}{l}\text { Behavioral } \\
\text { habit }\end{array}$} & \multicolumn{2}{l}{$\begin{array}{l}\text { Emotional } \\
\text { experience }\end{array}$} \\
\cline { 2 - 9 } & Before & After & Before & After & Before & After & Before & After \\
\hline Average & 32.13 & 34.58 & 19.48 & 20.39 & 19.07 & 21.15 & 22.31 & 25.38 \\
\hline Variance & 16.39 & 52.39 & 34.83 & 36.38 & 28.58 & 29.63 & 44.29 & 37.19 \\
\hline $\mathrm{t}$ & 1.8392 & 1.8372 & & 1.8938 & 1.8273 & \\
\hline $\mathrm{P}$ & 0.2693 & 0.0093 & 0.3948 & 0.3649 & \\
\hline
\end{tabular}

Through comparison of the data in the table, it shows that students generally think that physical exercise can make people happy and get physical and mental health, and also it can alleviate the anxiety, depression and other emotions, so as to achieve balance between mind and body. However, in the scores of the objective attitude and emotional experience, their performance of the experimental group before and after the test has obvious differences, the latter is better than the former. The common ground of the 2 dimensions is the objective motivation of students participating in the exercise, their self-experience and control ability.

There are three causes:

(1) The experimental group students focus on collaborative learning and the use of multimedia to learn independently, which improves their interest in learning and learning motivation. Meanwhile, the use of synchronous classroom group cooperation and independent online collaborative learning increases the interaction between students and teachers, students, and between students and computer, which is conducive to students' emotional exchanges and communication.

(2) Members of the cooperative group learn and exercise for the common learning objectives, so their goal is clearer and more definite, and any member consciously or unconsciously supervised by other team members.

(3) When participating in sports, people sometimes have to overcome the individual physiological or psychological barriers, and also to overcome various external difficulties. In the face of difficulties, some students easily choose to retreat or give up initiative learning and exercise.

\subsection{The Influence of the Multi PE Collaboration Model on the Academic Performance}

Table 7 gives the comparison results of learning achievement of the experimental group 
and control group, showing that in the evaluation score of standards and skills, experimental group is better than the control group. After statistical analysis, it shows that there is no significant difference between the two groups in scores of combinative skills ( $P>0.05$ ), indicating that the experimental factors have no influence on students' badminton combination scores. While in service and backcourt scores, there are significant differences between the two groups $(P<0.05)$, and the experimental group is higher than that of the control group, so the experimental teaching can improve the accuracy, standardization and rationality of student's service and backcourt lob technology. However, since the experimental period is very short and badminton exercise needs strong skill, which makes it difficult for students to master and complete the combination techniques movements well, that is way there exists no significant discrepancies between the two groups in combination scores.

There are three causes:

(1) $80 \%$ or more students of the experimental group and the control group choose Badminton Class for the first time, so all of them are beginners, leading to the low level of their standards achievement.

(2) the experimental period is very short, and playing badminton needs strong skill, which makes it difficult to improve the stability of skills in a short period of time, resulting in the low level of the standard results;

(3) Taking $\bar{X} \pm 3 S$ to carry out sampling error control, some students of high level will participate in the experiment and statistics, so the standard achievement also includes some students who are good at this sport.

Table 7. Comparison of Experimental Results between the Experimental Group and the Control Group

\begin{tabular}{|c|c|c|c|c|c|c|c|c|}
\hline \multirow{2}{*}{$\begin{array}{l}\text { Test } \\
\text { Index }\end{array}$} & \multicolumn{2}{|c|}{ Target achievement } & \multirow[b]{2}{*}{$\mathrm{t}$} & \multirow[b]{2}{*}{$\mathrm{P}$} & \multicolumn{2}{|c|}{ Skill assessment } & \multirow[b]{2}{*}{$\mathrm{t}$} & \multirow[b]{2}{*}{$\mathrm{P}$} \\
\hline & $\begin{array}{l}\text { Experime } \\
\text { ntal } \\
\bar{X} \pm S\end{array}$ & $\begin{array}{l}\text { Control } \\
\bar{X} \pm S\end{array}$ & & & $\begin{array}{l}\begin{array}{l}\text { Experim } \\
\text { ental }\end{array} \\
\bar{X} \pm S\end{array}$ & $\begin{array}{l}\text { Control } \\
\bar{X} \pm S\end{array}$ & & \\
\hline Service & $6.29 \pm 1.94$ & $5.18 \pm 1.91$ & 2.4984 & 0.0135 & $\begin{array}{l}84.49 \pm 4 \\
.78 \\
\end{array}$ & $\begin{array}{l}83.49 \pm 11 . \\
47\end{array}$ & 3.4952 & 0.0017 \\
\hline High ball & $5.23 \pm 2.17$ & $4.18 \pm 1.86$ & 2.3948 & 0.0483 & $\begin{array}{l}85.38 \pm 7 \\
.83\end{array}$ & $\begin{array}{l}83.48 \pm 11 . \\
54\end{array}$ & 2.4857 & 0.0097 \\
\hline $\begin{array}{l}\text { Combination } \\
\text { Technology }\end{array}$ & $8.39 \pm 4.59$ & $8.28 \pm 3.96$ & 0.2938 & 0.493 & $\begin{array}{l}79.38 \pm 7 \\
.49\end{array}$ & $\begin{array}{l}79.54 \pm 14 . \\
29\end{array}$ & 0.0018 & 0.4939 \\
\hline
\end{tabular}

\subsection{Association Rule Mining of multi PE Collaboration Model}

In order to verify that under the multi sports cooperation model, which factors are most related to students' learning interest, attitude and achievement, this paper adopts the association rule mining algorithm. At the same time, we use the cases of five students to effectively carry out the association rules mining, and the basic information of cases is shown in Table 8. 
Table 8. Basic Cases Information

\begin{tabular}{|l|l|l|l|l|l|}
\hline Index & Watch demo & Imitate drill & $\begin{array}{l}\text { Expert } \\
\text { guidance }\end{array}$ & $\begin{array}{l}\text { Mutual } \\
\text { evaluation }\end{array}$ & $\begin{array}{l}\text { Group } \\
\text { synchronization }\end{array}$ \\
\hline 1 & 1 & 1 & 0 & 0 & 1 \\
\hline 2 & 1 & 0 & 1 & 1 & 1 \\
\hline 3 & 0 & 1 & 0 & 1 & 0 \\
\hline 4 & 1 & 0 & 1 & 0 & 1 \\
\hline 5 & 0 & 1 & 0 & 1 & 1 \\
\hline
\end{tabular}

Table 9. Mining Results of Association Rules

\begin{tabular}{|c|l|}
\hline Effective association rules & Real association rules \\
\hline Group sync=>interest-1 & Group sync contribute to learn interest \\
\hline Group sync=>attitude-1 & Group sync contribute to learn attitude \\
\hline Group sync=>scores-1 & Group sync contribute to high scores \\
\hline
\end{tabular}

Through the association rules mining, the extraction of the frequent item sets, and the calculation of confidence and support, the calculation results are as shown in Table 9. It can be seen from the figure that in the learning under the multi sports writing model, adopting group cooperation classroom synchronization teaching mode achieves the best effect in the aspects of improving learning interest, attitude and academic achievement, which means that in practice, this kind of sports cooperation and learning method is the optimal, playing an vital role in the actual practice of PE teaching.

\section{Conclusions}

Multi PE collaborative learning breaks the traditional teaching mode, achieving the multi-directional cooperation and interaction between teachers and students, students and multimedia courseware, and students experts and students, which has a profound influence on students' ability, attitude, emotion, experience and other aspects. It can exert students' initiative, subjectivity and cooperation, helping to cultivate students' cooperation ability. Compared with the traditional learning methods, using multiple collaborative learning, students' interest in learning has significantly increased, and their exercise attitude also has improved. Through the teaching experiment, the three indexes, namely, the target attitude, behavioral perception and emotional experience of students towards exercise in the experimental group are all better than the control group. In addition, the school record of students in the experimental group has improved, showing a higher average level and a relatively concentrated trend, which are the best state. Effectiveness of multi sports collaborative learning is related to teaching methods, and the teaching effect of the cooperative classroom synchronization teaching is the best.

With the development of network technology, we hope that collaborative learning can become intelligent teaching and learning system with stronger interactive function, instant feedback function and information filtering function. According to the individual characteristics, the system can guide students to study. Thus realize individual teaching, and exhibit some intelligent characteristics of experts or teachers in a certain degree. Cooperative learning is student-centered autonomous learning mode, which does not mean that teachers will not put any restrictions on teachers. Teachers as the organizer, guider and facilitator of collaborative learning, should study on the way to give full play of their guiding role, which helps students to form a suitable and effective learning method to improve their autonomous learning ability and problem-solving ability, making the students to develop the learning habits of autonomous learning and also autonomous use of the network to carry out cooperative learning. 


\section{References}

[1] B. Zheng, M. Niiya and M. Warschauer, "Wikis and collaborative learning in higher education", Technology, Pedagogy and Education, vol. 24, no. 3, (2015), pp. 357-374.

[2] J. R. Savery, "Overview of problem-based learning: Definitions and distinctions", Essential readings in problem-based learning: Exploring and extending the legacy of Howard S. Barrows, (2015), pp. 5-15.

[3] F. Alonso, D. Manrique and L. Martínez, "Study of the influence of social relationships among students on knowledge building using a moderately constructivist learning model", Journal of Educational Computing Research, vol. 51, no. 4, (2015), pp. 417-439.

[4] A. S. Dadzie, M. Müller and A. Alissandrakis, "Collaborative Learning through Creative Video Composition on Distributed User Interfaces", State-of-the-Art and Future Directions of Smart Learning, Springer Singapore, (2016), pp. 199-210.

[5] E. M. Mercier, S. E. Higgins and A. Joyce-Gibbons, "The effects of room design on computer-supported collaborative learning in a multi-touch classroom", Interactive Learning Environments, vol. 24, no. 3, (2016), pp. 504-522.

[6] F. Kayalar, "Views of Teachers on the Benefits of After-School Programs and Summer Programs in terms of Social Emotional Learning", Merit Research Journal of Education and Review, vol. 4, no. 2, (2016), pp. 006-013.

[7] S. Beaudoin, J. P. Brunelle and C. Spallanzani, "The Journey of two Physical Education and Health Teachers in Learning to Teach Personal and Social Responsibility", Revue phénEPS/PHEnex Journal, vol. 7, no. 2, (2015).

[8] R. D. Vatavu and J. O. Wobbrock, "Formalizing agreement analysis for elicitation studies: new measures, significance test, and toolkit', Proceedings of the 33rd Annual ACM Conference on Human Factors in Computing Systems. ACM, (2015), pp. 1325-1334.

[9] C. Canova, E. Torre and M. Denker, "Significance Test for Detection of Sequences of Synchronous Events in Massively Parallel Spike Trains", Bernstein Conference 2015. Computational and Systems Neuroscience, (2015) (FZJ-2015-05868).

[10] G. Na, I. Han and N. Cho, "Fault Prediction of a Telecommunications Network using Association Rules Mining based on Voice of the Customer", Journal of the Korea Society of Digital Industry and Information Management, vol. 11, no. 4, , (2015), pp. 13-24.

[11] J. Yabing, "Research of an improved apriori algorithm in data mining association rules", International Journal of Computer and Communication Engineering, vol. 2, no. 1, (2013), pp. 25.

[12] M. Elena, "Social psychology adaptation of the personality of the girl teenager in the system of the motivational adequate requirement of the maintenance of the physical training", development, (2016).

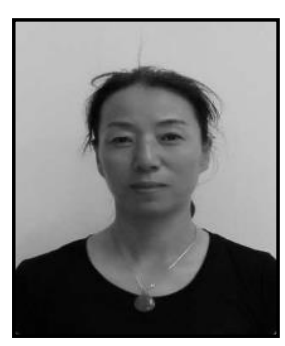

\section{Authors}

Ping Li, she was born in October, 1968. She has got the degree of Bachelor. Now, she is an associate professor of Department of Physical Education in Inner Mongolia University of Science \& Technology. Her main research direction is Physical Education.

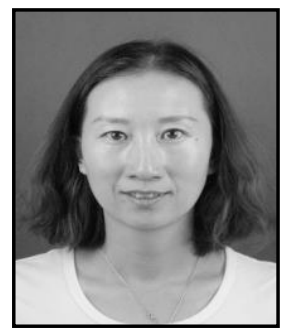

Linting Ma, she was born in March, 1980. She has got the degree of Bachelor. Now, she is a lecturer of Department of Physical Education in Inner Mongolia University of Science \& Technology. Her main research direction is Physical Education. 
International Journal of Database Theory and Application Vol.9, No.11 (2016) 